\title{
TRANSFORMAR LA ARQUITECTURA: GASPAR HERMOSO Y AMBROSIO DE FIGUEROA EN LA IGLESIA DE LA O DE TRIANA
}

\author{
TRANSFORMING THE ARCHITECTURE: \\ GASPAR HERMOSO AND AMBROSIO DE FIGUEROA \\ AT THE CHURCH OF LA O IN TRIANA
}

\author{
Pedro M. Martínez Lara \\ Universidad de Sevilla. España \\ pedrom@us.es
}

\begin{abstract}
La aparición de un memorial inédito que recoge las actuaciones de reparación y renovación de la iglesia de la $\mathrm{O}$, como consecuencia del terremoto de 1755 , ha permitido arrojar luz sobre el proceso constructivo de este singular inmueble, especialmente de su torre campanario, documentando a sus autores y la secuencia de las obras, así como algunos elementos destacados como los retablos cerámicos que la adornan.

Palabras clave: arquitectura sevillana; iglesia de la O; Ambrosio de Figueroa; Gaspar Hermoso; terremoto de 1755 .
\end{abstract}

The find of a new document that collects operations of restoring and renewal of the Church of la $\mathrm{O}$, as a result of the earthquake of 1755 , have allowed to shed light on the construction process of this singular building, especially of its Tower Bell, documenting their authors and sequence of works, as well as some elements emphasized as the ceramic altarpieces that embellish it.

Keywords: Sevillian architecture; Church of la O; Ambrosio de Figueroa; Gaspar Hermoso; 1755 earthquake.

\section{INTRODUCCIÓN}

Por su propia naturaleza, los procesos de transformación formal y estética de la arquitectura están indisolublemente ligados a las necesidades constructivas. En 
consecuencia, resultan habitualmente paulatinos y concentrados. En ocasiones, un hecho negativo como la destrucción masiva resultante de una catástrofe natural puede abocar a fenómenos creativos generalizados que a su vez posibilitan la aceleración de los aludidos procesos.

El seísmo que la mañana del primer día de noviembre de 1755 se dejó sentir con enorme intensidad en todo el suroeste de la Península Ibérica ha pasado a la historia como uno de los cataclismos de mayor impacto, a todos los niveles, de los últimos siglos. Pese a que su epicentro se situó a unos $200 \mathrm{~km}$ del cabo de San Vicente $^{1}$, su acción devastadora causó destrozos a lo largo de toda la costa peninsular atlántica, siendo Lisboa, con cuyo topónimo es hoy conocido el terremoto, una de las ciudades que se llevó la peor parte, quedando arrasada y su población diezmada. Con un nivel de destrucción ciertamente menor, las poblaciones del antiguo reino de Sevilla, especialmente su capital, sufrieron también las consecuencias del temblor como consta en diferentes crónicas y memoriales que se publicaron del suceso y sus efectos ${ }^{2}$.

Centrando la atención exclusivamente en el plano de la arquitectura, los cuantiosos derrumbes, desplomes, ruinas y daños de diversa consideración que se produjeron en edificios, supusieron de alguna manera una oportunidad para su renovación y actualización. Un proceso que no solo se desarrollaría en el aspecto constructivo sino también en el estético. Aunque fueron numerosos los daños estructurales, otros muchos percances afectaron a elementos decorativos y ornamentales, o a aquellos otros que sirven de soporte a estos, tales como remates, pináculos, chapiteles, campanarios, linternas, cúpulas, lucernarios... En consecuencia, la actividad constructiva derivada de la devastación se constituyó en espacio abierto a la creación, reformulando espacios, adaptando formas, redefiniendo tipologías, renovando y actualizando los repertorios y usos decorativos. En definitiva, transformando la arquitectura.

\section{EL TERREMOTO Y LAS FORMAS. HISTORIA E HISTORIOGRAFÍA}

"El día primero de noviembre de este dicho año, a las 10 de la mañana acaeció un universal y notable terremoto que duró más de diez minutos, asiendo en esta Ciudad mucho destrozo y particularmente en los templos, siendo este uno de los

${ }^{1}$ MARTÍNEZ SOLARES, José Manuel: Los efectos en España del terremoto de Lisboa (1 de noviembre de 1755). Madrid, 2001, pp. 22-ss.

2 MATUTE Y GAVIRIA, Justino: Anales eclesiásticos y seculares de la muy noble y muy leal ciudad de Sevilla. T. II. Sevilla, 1887, p. 122; ESPEJO CALA, Carmen: Datos para un repertorio de impresos sevillanos en torno al terremoto de 1755. Salamanca, 2008; y HERRERA GARCÍA, Francisco Javier: "«Terra tremuit et quievit». Los efectos del Terremoto de Lisboa en Andalucía Occidental y la renovación de la arquitectura dieciochesca”, en Terremoti e riconstruzioni tra XVII e XVIII secolo. Siracusa, 2012, pp. 79-86. 
que quedaron muy maltratados, pues sus arcos, bóvedas y claves quedaron tan destropeadas que de suyo hubiera venido a tierra y su torre demolido todo el último cuerpo. Y estando la Yglesia llena de gente fue Dios servido no peligrase nadie" 3 . De este modo se expresa, en un memorial conservado en el archivo histórico de la Archicofradía Sacramental de la O, el modo en que afectó y el alcance que tuvo el terremoto de 1755 en su iglesia. No obstante, otras versiones publicadas ofrecen datos diferentes: "De la O, todo desnudo el capitel de su Torre, cuyos fragmentos mataron a uno, que de este Templo salía"4.

Sea como fuere, parece que ambas fuentes coinciden en que hubo daños serios en la estructura del templo, siendo especialmente graves en la torre que habría perdido al menos el primitivo remate del que hoy muy poco o nada se sabe.

Construido entre 1699 y 1702 a expensas de los hermanos de la O, el inmueble, relativamente reciente en el momento del seísmo, sustituyó a una vieja capilla vinculada a la institución hospitalaria que dio origen a la actual corporación, que a su vez es propietaria del templo.

Como afirma Teodoro Falcón, y se deduce de la documentación conservada, el autor de las trazas fue Pedro Romero "el Viejo", a la sazón maestro mayor de fábricas del arzobispado de Sevilla, quien contó con la colaboración de tres de sus hijos: Félix, Diego y Pedro "el Mozo", en diversas tareas 5 . El edificio, construido fundamentalmente en ladrillo, apea los arcos que dividen sus tres naves de similar estatura en columnas de jaspe de Morón de la Frontera, de color encarnado, con basas y capiteles negros del mismo material, que Antonio Ramos, prioste de la hermandad, contrató con el cantero Antonio Gil Gataón, quien se encargaría también de la fachada, realizada en los mismos materiales ${ }^{6}$.

3 AHO (Archivo Histórico de la Archicofradía Sacramental de la O), secc. VI, Mayordomía, Clavería y Priostía, exp. 9, Breve descripción en que se manifiesta el principio que tuvo la redificación del Templo de Nuestra Señora de La O, s. f.; y PRIETO PÉREZ, Joaquín Octavio: "Un tiempo clave para la hermandad: 1685-1850", en Historia de la O. Una hermandad para un barrio. Sevilla, 2007, p. 116.

${ }^{4}$ RODRÍGUEZ GONZÁLEZ-OSSORIO, Pablo: Despertador, y recuerdo de dormidos, para que abran los ojos del alma, al gran golpe que padeció esta M. N. y M. L. Ciudad con el Terremoto acaecido en ella. Sevilla, 1755, p. 19.

5 FALCÓN MÁRQUEZ, Teodoro: "Pedro Romero (1638-1711), arquitecto del barroco sevillano", Laboratorio de Arte, 23, 2011, pp. 231-236.

${ }^{6}$ La documentación sobre estas obras en jaspe se conserva tanto en el archivo de la hermandad, donde se registran las cuentas, como en la sección de Protocolos Notariales del Archivo Histórico Provincial de Sevilla, en el que figuran las cartas de obligación y pago. AHO, secc. VI, Mayordomía, Clavería y Priostía, exp.7, Libro de cuentas de la Iglesia, Cofradía, Hermandad de la O, 1685-1707, ff. 7-ss; y AHPS (Archivo Histórico Provincial de Sevilla), secc. Protocolos Notariales, leg. 16.403, of. 23, libro $2^{\circ}$ de 1700, f. 908r-v; datos todos que fueron transcritos y publicados por primera vez en SANCHO 
Aparte de recoger el interesante proceso constructivo inicial, cada vez mejor conocido a la luz de la documentación, y la intervención en él de personalidades importantes en la historia de la arquitectura sevillana, la historiografía de la iglesia de la $\mathrm{O}$ se ha ocupado también de la cuestión estética y estilística a propósito de este edificio ${ }^{7}$. En efecto, diversos autores han detectado desde siempre que, tras los daños del terremoto de 1755, se produjeron operaciones de renovación arquitectónica, cuya realidad y alcance ha sido abordada unas veces desde la certera intuición y otras a partir de indicios formales. Centrando la atención en estas intervenciones, un azulejo que contiene la imagen de san Andrés situado en la caña de la torre de la iglesia de la O ya advierte de que esta "SE ACABÓ A.1699/ SE RENOBÓ A. 1756", y así lo refleja Matute aunque sin aportar autorías ni el alcance de esa renovación ${ }^{8}$. Por su parte, Sancho Corbacho repara en

CORBACHO, Heliodoro: Documentos para la Historia del Arte en Andalucía. T. VII. Sevi1la, 1934, pp. 37-38 y 116-118, y que han sido utilizados por toda la bibliografía posterior.

${ }^{7}$ Las primeras referencias a la arquitectura de este templo se encuentran en obras ya clásicas, que desde una metodología eminentemente descriptiva trasladan la realidad del mismo. MATUTE Y GAVIRIA, Justino: Aparato para describir la Historia de Triana $y$ de su iglesia parroquial. Sevilla, 1818, pp. 78-84; GONZÁLEZ DE LEÓN, Félix: Noticia artística, histórica y curiosa de todos los edificios públicos, sagrados y profanos de esta Muy Noble, Muy Leal, Muy Heroica e Invicta Ciudad de Sevilla, y de muchas casas particulares. T. II. Sevilla, 1844, pp. 360-361; y GESTOSO y PÉREZ, José: Sevilla Monumental y Artística. T. III. Sevilla, 1892, pp. 409-411. La publicación en 1934 de los ya referidos documentos relativos a las obras de cantería y albañilería del templo abrió el campo a la investigación moderna sobresaliendo la monografía de Sancho Corbacho sobre la arquitectura barroca del siglo XVIII en Sevilla, donde se incluye el estudio formal de diferentes elementos de la iglesia de la O. SANCHO CORBACHO, Antonio: Arquitectura barroca sevillana del siglo XVIII. Madrid, 1952. Más recientes son los trabajos de FALCÓN MÁRQUEZ, Teodoro: "Una Arquitectura para el culto", en Sevilla Penitente. T. I. Sevilla, 1995, pp. 249-250; y GARCÍA DE LA CONCHA DELGADO, Federico: "Pontificia, Real e Ilustre Archicofradía del Santísimo Sacramento, Nuestro Padre Jesús Nazareno y María Santísima de La O”, en Nazarenos de Sevilla. T. I. Sevilla, 1997, pp. 425-ss. Con motivo de la coronación canónica de la titular dolorosa de la corporación, se editó un libro colectivo donde se abordan los aspectos históricos, constructivos y artísticos del inmueble en diferentes capítulos. PRIETO PÉREZ, Joaquín Octavio: "Un tiempo clave...", op. cit.; y JUSTO ESTEBARANZ, Ángel: "El arte y la música de culto interno", en Historia de la O. Una hermandad para un barrio. Sevilla, 2007, pp. 375-377. En AA.VV.: Guía artística de Sevilla y su provincia. T. I. Sevilla, 2004, pp. 335-336, se repite prácticamente la misma información de la edición de 1981. Sin duda, es el ya citado trabajo de Falcón el que ofrece la información más actualizada, ordenada y con abundantes referencias documentales en lo que a la arquitectura se refiere. FALCÓN MÁRQUEZ, Teodoro: "Pedro Romero (1638-1711)...”, op. cit.

${ }^{8}$ MATUTE Y GAVIRIA, Justino: Aparato..., op. cit., p. 81. 
lo singular del remate o chapitel de la torre cuya cronología mantiene en $1699^{9}$, quizá entendiendo que las obras de renovación no modificaron las formas originales. Resulta curioso cómo la intuición de su análisis formal lo lleva a encuadrar el chapitel de la $\mathrm{O}$ entre diferentes obras entre las que figuran algunas de la familia Figueroa, como son los remates de las torres del patio del colegio de San Telmo o la torre de la parroquia de Las Cabezas de San Juan ${ }^{10}$. No es hasta 1995 cuando se aborda por primera vez la intervención en la torre como consecuencia del terremoto de 1755. Concretamente, Falcón apunta a un diseño de Pedro de Silva ${ }^{11}$. Por su parte, García de la Concha aportó en 1997 los nombres de Gaspar Hermoso, como maestro alarife responsable de la recomposición de la torre, y de Juan Bernardo y Gaspar de Baeza, como ceramistas a los que habría correspondido el alicatado de la misma, aunque no revela la fuente de esas informaciones $^{12}$. Más tarde, en 2011, Falcón se reafirma nueva y sólidamente en la tesis de la dirección de obra de Pedro de Silva, añadiendo que la ejecución correspondió a Gaspar Hermoso mientras que los encargados de colocar los azulejos fueron los citados Juan Bernardo y Gaspar de Baeza ${ }^{13}$. Por lo demás, el resto de autores que han abordado este asunto se han limitado a seguir o exponer las teorías citadas.

\section{TRANSFORMANDO LA ARQUITECTURA}

Consta que en el cabildo general celebrado el 9 de noviembre se informó a los hermanos de la situación ruinosa de la iglesia y su torre, y que, ante la falta de recursos económicos suficientes, se exhortó a estos para salir a pedir a la calle

${ }^{9}$ SANCHO CORBACHO, Antonio: Arquitectura barroca..., op. cit., p. 31.

${ }^{10}$ Ibidem, p. 33. Sobre las obras aludidas y su pertenencia al quehacer de los Figueroa puede consultarse una amplia bibliografía entre la que cabe destacar FALCÓN MÁRQUEZ, Teodoro: El Palacio de San Telmo. Sevilla, 1991; HERRERA GARCÍA, Francisco Javier y QUILES GARCÍA, Fernando: "Nuevos datos sobre la vida y la obra de Leonardo de Figueroa", Archivo Español de Arte, 65, 259, 1992, pp. 335-350; ARENILLAS, Juan Antonio: Ambrosio de Figueroa. Sevilla, 1993; RIVAS CARMONA, Jesús: Leonardo de Figueroa: una nueva visión de un viejo maestro. Sevilla, 1994, p. 90; ÁLVAREZ, VILAR, Francisco Javier: Una catedral para un pueblo. Estudio histórico artístico de la parroquia de San Juan Bautista de Las Cabezas de San Juan (Sevilla). Sevilla, 1996; y MORALES MARTÍNEZ, Alfredo J.: "Leonardo de Figueroa y el barroco polícromo en Sevilla", en Figuras e imágenes del Barroco. Estudios sobre el barroco español y sobre la obra de Alonso Cano. Madrid, 1999, pp. 193-212.

${ }^{11}$ FALCÓN MÁRQUEZ, Teodoro: “Una Arquitectura...”, op. cit., p. 250.

12 GARCÍA DE LA CONCHA DELGADO, Federico: "Pontificia, Real e Ilustre...", op. cit., p. 425.

13 FALCÓN MÁRQUEZ, Teodoro: "Pedro Romero (1638-1711)...”, op. cit., p. 236. 
con las demandas de la hermandad en busca de financiación de las obras ${ }^{14}$. El estudio de un expediente que se conserva en el archivo histórico de la Archicofradía Sacramental de la O y que lleva por título "Obra que se hizo a la Iglesia de Ntra. Sra. de la $\mathrm{O}$ a causa del daño que le ocasionó el terremoto del día primero de Noviembre del año 1755, la que administró Diego Antonio Quadrado, Fiscal de dicha hermandad y ejecutada por el maestro Gaspar Hermoso que lo es de Albañilería de la dicha hermandad"15 (Figura 1), hasta ahora completamente inédito, ha permitido analizar de manera pormenorizada los trabajos que se llevaron a cabo en la iglesia de la $\mathrm{O}$ y su torre, aportando un considerable caudal de conocimiento sobre este proceso constructivo y los usos arquitectónicos que estaban vigentes en aquel momento.

Yendo directamente al contenido del documento, del cual se ofrece amplio extracto de su transcripción en el apéndice documental, queda atestiguado que tan solo dos días después del seísmo, es decir, el primer lunes siguiente, acudió a la iglesia Ambrosio de Figueroa en calidad de "maestro y alcalde alarife de esta ciudad" 16 , como consta en el recibo (Figura 2) que se conserva anexo al aludido memorial, "para disponer la obra della y bajo su disposición se hizo". Parece claro que el maestro Figueroa efectuó la inspección general del edificio siniestrado, evaluando daños y estableciendo prioridades de actuación como director de la obra. Para 1755, Ambrosio contaba ya con 53 años, una sólida formación

${ }^{14}$ AHO, secc. IV, Cabildos, exp. 4, Libro en que se escriven los Cavildos que esta Sta. Hermd de Jesus Nazareno y nra Señora de la O Celebra. El que se comenso el Año de la Encarnacion del Señor de 1753, s. f.; y PRIETO PÉREZ, Joaquín Octavio: "Un tiempo clave...”, op. cit., p. 116.

15 AHO, secc. VI, Mayordomía, Clavería y Priostía, exp. 35, Obra que se hizo a la Iglesia de Ntra. Sra. de la O a causa del daño que le ocasionó el terremoto del día primero de Noviembre del año 1755, la que administró Diego Antonio Quadrado, Fiscal de dicha hermandad y ejecutada por el maestro Gaspar Hermoso que lo es de Albañilería de la dicha herman$\mathrm{dad}$. Una pequeña parte del contenido de este documento original había sido copiado por el periodista e historiador Rafael Díaz Díaz, quien durante al menos las dos últimas décadas del siglo XX recopiló informaciones en el archivo de la hermandad de la $\mathrm{O}$ con la intención de componer una monografía sobre la historia de la corporación del que constan algunos capítulos redactados y que quedó inédita tras su fallecimiento. Este material, compuesto de manuscritos, papeles mecanografiados y fotocopias de documentos, que se conserva parcialmente en el archivo de la hermandad, pudo ser la fuente de algunas de las hipótesis planteadas por la historiografía.

${ }^{16}$ El recibo, por valor de 120 reales, firmado y rubricado por Ambrosio de Figueroa, fue abonado el 18 de mayo de 1757 y su tenor es el siguiente: "Digo yo Ambrosio de Figueroa maestro alcalde de alarife de esta ciudad que recibí del señor Diego Quadrado, fiscal de la hermandad de nuestra señora de la o ciento veinte reales de vellón por la visita que hice a la iglesia y a la obra de ella y para que conste doy el presente en Sevilla en 18 de mayo de 1757 años. Son 120 rs. Ambrosio de Figueroa (rub)”. AHO, secc. VI, Mayordomía, Clavería y Priostía, exp. 35. 
a la sombra de su padre, Leonardo de Figueroa y de su hermano mayor Matías José, y una amplia experiencia colaborando en los numerosos encargos de su padre así como maestro de obras de albañilería en solitario o a las órdenes de otros arquitectos como Diego Antonio Díaz ${ }^{17}$.

Ese mismo día 3 de noviembre acudió a la iglesia de la $\mathrm{O}$ el también maestro alarife Gaspar Hermoso, encargado de ejecutar las obras según lo establecido por Figueroa, junto con tres peones que de inmediato se pusieron manos a la obra, empleando la primera semana en construir los andamios de la nave central y efectuar una composición de urgencia de la parte del tejado "que estaba desbaratado del remate de la torre que le cayó encima". Al mismo tiempo se hizo la provisión de los materiales de construcción necesarios para emprender la obra, que comenzó en cuanto estuvieron listos los andamios. El exhaustivo apunte del memorial de las obras permite conocer con gran detalle el progreso de los trabajos: la semana siguiente se realizaron operaciones de alzado de claves y recomposición de los arcos en peor estado, los más próximos a la torre y coro, así como también el arreglo de la bóveda de este. A continuación el equipo formado por el maestro y dos peones avanzaron sus trabajos hacia el altar mayor realizando actuaciones de índole similar a las anteriores. Las dos semanas siguientes fue el turno de la nave del sagrario, es decir, la del evangelio en toda su amplitud en primer lugar y la de la capilla de Jesús en el lado de la epístola, "del lado del río", terminándose así el año de 1755. Resulta interesante advertir en este punto cómo queda registrado un cese de la actividad coincidiendo con la festividad de la titular de la iglesia, que se celebra el 18 de diciembre. Finalmente, la primera semana de 1756 se resanaron con yeso todas las roturas - grietas- de las bóvedas de la iglesia.

A partir de este momento se paraliza la actividad en la iglesia hasta el 27 de julio de 1756, cuando se reanudan los trabajos acometiendo entonces la fachada y puerta. Ya en el mes de septiembre se vuelve a actuar sobre los tejados de la iglesia, "que con la obra de la torre se rompieron las tejas". De igual modo, entre el 9 y el 13 de septiembre de ese año "pusieron los liensos de Jesús y de San Andrés los que están a el pie de la torre". El apunte se refiere a dos de los retablos cerámicos que hoy se contemplan en la caña de la torre, concretamente el de mayor tamaño de todos, que representa a Nuestro Padre Jesús Nazareno, titular de la hermandad de la $\mathrm{O}$, y el que con la efigie de San Andrés va acompañado del rótulo y fechas que datan las actuaciones constructiva y renovadora de la iglesia y torre (Figuras 3 y 4 ).

A continuación la relación de cuentas retrocede en el tiempo hasta el 14 de noviembre de 1755 para registrar los trabajos de Diego de la Rosa, maestro escultor que estuvo encargado de componer "la talla de yeso de la iglesia", aprovechando los andamios colocados la semana anterior en la nave central y a la vez

${ }^{17}$ ARENILLAS, Juan Antonio: Ambrosio de Figueroa, op. cit., p. 39. 
que se ejecutaban las labores de consolidación estructural de los arcos con que se cierra ese espacio. Estas yeserías habían sido ejecutadas por Félix Romero cincuenta y cinco años antes ${ }^{18}$. A finales del mes de marzo, Juan Tejerizo, pintor y dorador que poco tiempo después emprendería el dorado del retablo mayor de la iglesia ${ }^{19}$, realizó junto a Miguel Fernández diversas actuaciones de "retocado" al "estofado de la capilla mayor" en alusión a la decoración de pintura mural, hoy desaparecida, que decoraba la bóveda sobre el presbiterio. La obra de la iglesia se da por concluida en abril de 1756 con los trabajos realizados por el maestro Miguel de la Puerta en la portada del templo.

A continuación, el memorial expone la "obra que se le hizo a la torre de la iglesia en el remate y renuevo della que arruinó el terremoto acaecido el día primero de noviembre del año de 1755 hecha por el maestro Gaspar Hermoso" que comenzó el 20 de mayo de 1756 y que finalizaría en la víspera de la festividad de Nuestra Señora de la $\mathrm{O}$ de ese año. Las primeras operaciones fueron de montaje de andamios, preparación y resanado de los paramentos a intervenir, así como el acopio de materiales. Consta que la cruz y algunos remates consiguieron salvarse y se repararon para ser reutilizados, si bien esta cruz, veleta y corona que doró el maestro Miguel de la Puerta y que fueron colocadas justo un año después de su ruina, fueron sustituidas en $1863^{20}$. Consta igualmente que se fue trabajando de arriba abajo, componiendo con ladrillos el volumen del nuevo remate, siendo después alicatado de azulejos blancos y azules. También se cortaron las cornisas y se compuso todo el alicatado. Los trabajos de renovación de esta arquitectura concluyeron con la instalación del "lienzo de la Virgen", es decir, el retablo cerámico que representa a La Virgen imponiendo la casulla a San Ildefonso, hecho milagroso que acaeció el día 18 de diciembre, festividad de Nuestra Señora de la O (Figura 5).

Otros azulejos fueron colocados en la base del campanario que representaban, según el memorial, a Santa Bárbara y Santa Brígida. De ellos, el último se conserva en el paño central de la predela del campanario, que mira a la calle Castilla, flanqueado por los que representan a San Antonio y a San José. Mientras

${ }_{18}$ AHO, secc. VI, Mayordomía, Clavería y Priostía, exp.7, Libro de cuentas de la Iglesia, Cofradía, Hermandad de la O 1685-1707, f. 15: "Yten 828 rs. que dio a Félix Romero por el trabajo de 34 días y medio que se ocupó en hacer los florones y tallado de la nave principal, a 12 rs. cada uno". Citado por FALCÓN MÁRQUEZ, Teodoro: "Pedro Romero (1638-1711)...”, op. cit., p. 234, nota 37.

${ }_{19}$ El dorado se inició en 1755 y se prolongaría hasta al menos 1765 cuando aún se realizan pagos por estos trabajos. AHO, secc. VI, Mayordomía, Clavería y Priostía, exp. 48, Recados de las Quentas del dorado del retablo de Ntra Sra de la O que da el Prioste Diego Moreno Rodríguez.

${ }^{20}$ Consta en las cuentas de ese año el pago "por la corona para la cúpula de la torre: 30 r., por el plomo para dicha corona 16 libras, 32 r.”. AHO, secc. VI, Mayordomía, Clavería y Priostía, exp. s. n., Recados de cuentas de 1863. 
tanto, en el que mira hacia la cabecera del templo se conserva en el paño central un fragmento del que representaba a las santas Justa y Rufina y a los lados San Gabriel y San Miguel arcángeles. Se desconoce si estos otros paneles fueron incorporados más adelante o bien datan de antes del terremoto de 1755 .

\section{CONCLUSIÓN}

A la vista de lo contenido en el documento que se aporta, parece probado que, al menos en los trabajos referentes a la iglesia de la O, fue Ambrosio de Figueroa quien se encargó de la toma de decisiones y aportar las soluciones constructivas pertinentes para subsanar los daños estructurales del templo, en un momento en el que todos los arquitectos y maestros alarifes de la ciudad vieron multiplicada su dedicación a causa de los cientos de inmuebles que había que examinar y dictaminar para después proponer actuaciones ${ }^{21}$. Quizá fuera también Figueroa el maestro "que trazó el dicho remate y cortó las 4 cornisas que dicho remate tiene" y por lo que se le pagaron 85 reales por los ocho días y medio que se ocupó de ello. Lo que sí parece claro es que a raíz de las intervenciones realizadas en diversos edificios como consecuencia de los daños provocados por el terremoto de 1755 , su carrera fue progresivamente en ascenso hasta su fallecimiento en $1775^{22}$.

Por su parte, Gaspar Hermoso se revela en la documentación como el maestro alarife de confianza de la corporación trianera pues no solo se le confía la dirección y ejecución de obras de magnitud como las que aquí se refieren, sino también de forma muy habitual, los reparos que se efectuaban en las casas y fincas propiedad de la hermandad.

A propósito del azulejo que representa a Nuestro Padre Jesús Nazareno (Figura 3), el memorial que aquí se aporta permite adelantar la fecha de su realización y colocación, así como documentar su factura. Hasta ahora se había mantenido la fecha de 1760 para su realización y colocación, pero después de un pormenorizado análisis del retablo cerámico, puede comprobarse cómo el azulejo va orlado por una cenefa de roleos en color ocre sobre fondo azul cobalto. Este adorno, cuya anchura no supera nunca la de la pieza cerámica que la contiene, se ve interrumpida en la fila inferior de azulejos, que bien pudieran haberse sustituido cuatro años más tarde de su colocación original para introducir el rótulo

${ }^{21}$ En las cuentas que rindió el fiscal Diego Cuadrado el año de 1756, aparecen dos recibos más firmados por Ambrosio de Figueroa, quien en compañía de Gaspar Hermoso en el primero y de Agustín de Chaves en el segundo había acudido a visitar y medir "un pedazo de sitio" correspondiente a las casas del número 35 del protocolo de la hermandad de la O. AHO, secc. VI, Mayordomía, Clavería y Priostía, exp. 30, Recado de las cuentas que dio Diego Antonio Cuadrado fiscal de la hermandad de Nuestra Señora de La O en este año de 1756.

${ }^{22}$ ARENILLAS, Juan Antonio: Ambrosio de Figueroa, op. cit., p. 25. 
que contiene la controvertida fecha: "HIJAS DE JERUSALÉN NO LLOREIS POR MÍ, SINO LLORAD POR VOSOTRAS MISMAS Y POR VUESTROS HIJOS. AÑO DE 1760". La grafía tampoco coincide con la del azulejo dedicado a San Andrés de la misma mano y en la misma fecha. Se ha podido esclarecer que el autor de los "bedriados" de los azulejos es el alfarero Juan Bernardo, a la sazón hermano de la $\mathrm{O}$, quien dio como limosna buena parte del fruto de su trabajo. De otro lado, se sabe que el autor de la pintura es José de Zúñiga, pintor ceramista hasta ahora desconocido, al que se le abonan 60 reales por su labor. Lo que cada vez es menos probable es que se realizara un panel de azulejos en 1756 y posteriormente otro en 1760 para sustituirlo.

Con relación a las formas presentes en la torre campanario de la iglesia de la O (Figura 5), el diseño del alzado del cuerpo de campanas puede considerarse, según señala Falcón, un precedente de lo proyectado por José Tirado y Juan Gómez en San Román ${ }^{23}$. No obstante, la formulación de las salomónicas que articulan esta pieza, especialmente en las espiras y capiteles, está en directa relación con lo realizado por Leonardo de Figueroa tanto en la espadaña de la iglesia del real convento de San Pablo, hoy parroquia de la Magdalena, en 1697, como con las presentes en el patio de San Acacio, del mismo autor en la misma década. De igual modo, cerrando el círculo y en cumplimiento de la intuición de Antonio Sancho Corbacho, el "raro" chapitel bulboso de esta torre de la O mantiene claras dependencias con obras en las que participó Ambrosio de Figueroa en particular, como la torre de la parroquial de Las Cabezas o la cúspide de la capilla de afuera del monasterio de la Cartuja de las Cuevas, si bien existe la misma relación con otras en las que intervendrían otros miembros de su familia, como las torres del patio del colegio de San Telmo.

En suma, podría considerarse que el contexto arquitectónico de la Sevilla del siglo XVIII es un universo en el que resulta extremadamente complicado asignar formas específicas a un maestro concreto, puesto que se trata de un ambiente en el que domina la inspiración en las fuentes gráficas, y a la vez se producen préstamos, citas, versiones y evoluciones de un amplio repertorio compositivo y creativo. La torre de la $\mathrm{O}$, con la armoniosa composición realizada en dos tiempos y a varias manos de su campanario y chapitel, es viva muestra de esta circunstancia.

\section{APÉNDICE DOCUMENTAL}

\section{Documento $1^{24}$}

${ }^{23}$ FALCÓN MÁRQUEZ, Teodoro: “Pedro Romero (1638-1711)...”, op. cit., p. 236.

${ }^{24}$ Dada la limitación de espacio, la extensión del documento y lo reiterativo de su contenido, se ha optado por extractar la información en busca de una mayor claridad, resumiendo los conceptos repetidos. 
Obra que se hizo a la Iglesia de Ntra. Sra. de la O a causa del daño que le ocasionó el terremoto del día primero de Noviembre del año 1755, la que administró Diego Antonio Quadrado, Fiscal de dicha hermandad y ejecutada por el maestro Gaspar Hermoso que lo es de Albañilería de la dicha hermandad.

AHO (Archivo de la Hermandad de la O), sec. VI, exp. 35, leg. 12 (6), s. f.

Materiales que se gastaron en la obra de dicha iglesia

Cal

Día 3 de noviembre se trajeron 10 cargas de cal a 71/2 la carga - 75 rs.

Día 28 cocho cargas a 10 rs. - 80rs.

Yten. se gastaron más 4 cargas que dio don Sebastián Echarde Administrador de la Almona

155 rs.

Yeso

Se compró primeramente 7 quintales

De yeso a 4 reales el quintal - 28 rs.

Día 13 de Noviembre, 6 quintales - 24 rs.

Día 19, ocho quintales - 32 rs.

Día 28, seis quintales -24 rs.

Día 6 de diciembre, 7 quintales - 28 rs. //

Día 12 quatro quintales a cuatro - 12 rs.

Por 10 cargas de arena a 6 qtos. -007 rs.

159. 2 rs.

Yeso blanco

Por 3 quintales de yeso blanco a Lora - 30rs.

189. 2 rs.

Cal de Moron

Por 4 almudes de cal a un rs. -4 rs.

Por 6 almude a 7 qtos. -4.32 rs.

Por otros 4 almudes -3.1 rs.

Por 6 almudes -4.32 rs.

Por 7 a 7 qtos. -5.26 rs.

223.2 rs.

Madera

Por 2 berlingas de 7 varas para los andamios de la Iglesia a 11 rs. - 22 rs.

Por un palo de 8 varas para levantar los claves de los arcos - 15 rs.

Por 8 tablas alquiladas -8 rs.

45 rs.

Tralletas y espuertas

Por 8 espuertas cubicas a 6 qtos -5.22 rs.

Por 2 cargaderas -3 rs.

Por 15 masillos de trayeras a 7 qtos. -12.12 rs. 
Por otros 6 masillos y un tiro - 14. 17 rs.

35. 17 rs.

Clavos

Por 100 clavos de entablar -4 rs.

Por 100 de alfagia - 6 rs.

10 rs.

Canal

Por 400 canales a 10 rs. El 100 - 40 rs.

Por 25 canales de vuelo - 12 rs.

Jornales de albañilería

Día 3 de noviembre, trabajó el maestro y tres peones. El maestro 7 rs. y los peones a 5 y un muchacho $3 \frac{1}{2}-25.17 \mathrm{rs}$.

Día 4 el maestro a 7 rs. 3 peones a 5 rs. y un muchacho a $3 \frac{1}{2}--25.17$ rs.

Día 5 el maestro y tres peones a $4 \frac{1}{2}$ y el muchacho a $3 \frac{1}{2}--24$ rs.

Día 6 el maestro y 3 peones y muchacho - 24 rs.

Este dicho día trabajaron 3 muchachos, dos de $31 / 2$ y uno de 3 rs. para traer la madera para los andamios

Día 7 el maestro tres peones a 4 1 12 y 2 muchachos a 3 1/2 -- 27.17 rs.

Día 8 los dichos - 27.17 rs.

En estos 6 días se compuso el tejado de la iglesia que estaba desbaratado del remate de la torre que le cayó encima y se hicieron los andamios en la nave de en medio.

Desde el día 9 hasta el día 15 de noviembre trabajó el maestro con 3 peones a $4 \frac{1}{2}$-- 20.17 rs. por día.

En estos 7 días se compusieron los dos arcos de junto al coro que tenían vencidos los claves y el remate de la bóveda de aquella nave y el del coro bajo.

Desde el día 17 hasta el 19 de noviembre: el maestro y tres peones a 4 1/2 -20.17 rs. por día.

En estos 6 días se compusieron los arcos de el altar mayor que tenían los claves vencidos y el bovedado del cañón de en medio y capilla mayor, las dos ventanas y presbiterio.

Desde el 1 hasta el 7 de diciembre el maestro y dos peones a 4 1/2 -- 16 rs. por día.

En estos 7 días quedó rematada la nave del sagrario hasta el altar de Santa Bárbara quedando el bovedado della tapadas las aberturas y resanadas por abajo.

Desde el día 9 hasta el 13 y desde el 22 al 29 de diciembre los dichos - 16 rs. por día.

En estos 8 días se [roto] nave del lado del rio desde la capilla de Jesús hasta el altar de la cruz hecha la misma obra de la nave de la Calle - 670 rs.

Desde el día 30 de diciembre hasta el 8 de enero el maestro y tres peones a 4 1/2 -- 20.17 rs. por día. En estos 8 días se resanaron con yeso las bóvedas por arriba por todas las roturas 
Desde el día 27 de julio hasta el 15 de agosto el maestro y 3 peones a 4 rs. -19 rs. por día. En estos 16 días se compuso la puerta de la iglesia por de dentro y fuera y se renovó la fachada de la calle,

Desde el día 1 al 7 de septiembre el maestro y tres peones - 19 rs. por día.

En estos 6 días se hizo la obra del tejado de la iglesia que con la obra de la torre se rompieron las tejas.

Desde el día 9 al 13 de septiembre el maestro y dos peones - 15 rs. por día.

En estos 5 días se pusieron los liensos de Jesús y de San Andrés los que están a el pie de la torre.

En esta obra de la iglesia se gastaron ocho jornales de carpintería a 7 rs. - 56 rs. 1383 rs.

Jornales que gastó el maestro Diego de la Rosa escultor en la compostura de la talla de yeso de la iglesia,

Primeramente trabajó el maestro el día 14 de noviembre el dicho maestro y se le dio de jornal - 7 rs.

Desde el día 15 hasta el 28 de noviembre 15 - 7 rs. por día.

Desde 1 al 3 de diciembre -7 rs. por día.

Días 27 y 28 de febrero de 1756 - 7 rs. por día.

Desde el día 1 al 4 de marzo - 7 rs. por día.

Retocado que hizo al estofado de la capilla mayor el maestro

Juan Texerizo y Miguel Fernández - 154 rs.

Desde el día 29 de marzo trabajaron los dichos hasta el 1 de abril y se les dio de jornal a 7 rs. -14 rs. por día.

Materiales

Por 3 libros de oro - 30 rs.

En aceite y pinturas -20.8 rs.

1608 rs.

Retocado de la obra de la puerta de la iglesia del lado de [roto] hecha por el maestro Miguel de la Puerta

Materiales

Por libra y media de aceite de linaza - 2.32 rs.

Por $2 \frac{1}{2}$ libras de albayalde a 16 qto.

Por una libra de Almagra - 1.8 rs.

Por el trabajo del dicho maestro - 15 rs.

El oro de la o se dio de limosna

Por componer dicho maestro las basas de dos columnas que se rompieron -6 rs.

Por pintar algunos remiendos del jaspeado de la Yglesia - 2.17 rs.

Por 3 libras de ocre para pintar la puerta el jaspeado de la fachada de la calle -- 2.28 rs.

Por 3 libras de belas de cebo para el trabajo de las bóvedas del techo a treze quartos la libra -4.20 rs.

39.27 rs. 
Yten mas al maestro Ambrosio de Figueroa que lo es de alarife de el número de esta ciudad por la visita que fizo el día 3 de noviembre a la Yglesia y para disponer la obra de ella y bajo de su disposición se hizo - 120 rs.

Suma General del Gasto

En cal se gastó - 155 rs.

En yeso y dos cargas de arena -- 189.2 rs.

En cal de Morón - 22.32 rs.

En Madera - 43 rs.

En sogas y espuertas -35.17 rs.

En clavos - 10 rs.

En canales - 50 rs.

En jornales de albañilería, carpintería y peones - 1.383.17 rs.

En el tallista del yeso - 154 rs.

En el retocado de la capilla mayor - 106.8 rs.

En el retocado de la puerta de la iglesia y otras cosas - 39.27 rs.

A el maestro Figueroa - 120 rs.

2.313 rs.

Monta la obra de la iglesia como parece del sumario general dos mil trescientos trece reales y un maravedí de vellón.

Obra que se le hizo a la torre de la iglesia en el remate y renuevo della que arruinó el terremoto acaecido el dia primero de noviembre del año de 1755 hecha por el maestro Gaspar Hermoso en la forma siguiente.

Materiales gastados en la obra

Madera, día 20 de mayo del 1756

Primeramente se trajeron de casa de Bernardo Ruiz maderero 47 berlingas alquiladas a un rs. $-47 \mathrm{rs}$.

Por 6 mechinales de alquiler -6 rs.

Por 6 tablas de Flandes -6 rs.

Traidura y llevada de la madera en 7 mandados de un caballo - 14 rs.

Dos ojas de de tabla con traidura -9.26 rs.

82.26 rs.

Hierro

Por 100 clavos de alfagra -7.17 rs.

Por 100 de entablar - 4 rs.

Por una rasqueta que se hizo para rascar la torre -3 rs.

14.17 rs.

Por una lima para arreglar la cruz de la torre -- 2.28 rs.

Por barra y $1 / 2$ de tiradillo para los remates de la torre - 15 rs.

Por componer otros hierros de los remates de la torre y hacer otros nuevos -23 rs.

Cal 
Se gastaron en la dicha obra 5 cahices de cal que dio de limosna el señor don Sebastián echarde, administrador de la almona

Cal de Morón

Por 5 almudes de cal a 7 qtos. -4 rs.

Yeso

Por 5 quintales del yeso -17.17 rs.

21.13 rs.

Arena

Por 5 cargas de arena a 7 qtos. -4.2 rs.

Ladrillo

Por 500 ladrillos gordos -45 rs.

Por 175 ladrillos raspados -17.17 rs.

Por 5 cornisas a 6 rs. -30 rs.

Por 30 medias cornisas para el cuerpo nuevo de la torre - 68 rs.

Por dos ladrillos que llaman abiertos de colmenas - 10 rs.

Por otras 12 cornisas que dio el hermano Juan Bernardo - 20rs.

Tralletas y espuertas

8 Macillos de tralletas -6.20 rs.

4 Espuertas

Se gastaron más 30 macillos de tralletas que se juntaron de limosna y una cargadera -10.30 rs.

Azulejos

Por 400 azulejos crudos a 4 rs. -16 rs.

Por 200 a $4 \frac{1}{2}--3$ rs.

Por 800 a $3 \frac{1}{2}$-- 28 rs.

Por 200 a 3 rs. -6 rs.

Por 500 berduguillos a $21 / 2$-- 12.17 rs.

Por 20 azulejos cocidos y bedriados que dio el hermano José de Almanza de valor de 14 rs. en precio de 7 rs. -7 rs.

Todos los dichos azulejos se compraron crudos, se daban a cocer y bedriar de limosna

Por la cosidura de la corona y remates en casa de Gaspar de Baeza -- 80 rs.

Por traer y llevar los dichos remates -3 rs.

Los demás lienzos del remate, el de la Virgen, de Jesús, Santa Bárbara, Santa Brígida y San Andrés, su bedrío y cocidura apreciado en 300 rs. que dio de limosna el maestro y hermano Juan Bernardo.

176.17 rs.

Pintura que se gastó en la torre

Por 3 libras de albín - 7.2 rs.

Por 6 libras de Almagra a 10 qtos. 7.2 rs.

Por 5 libras de ocre a 127.2 rs.

Una libra de Azareon - 2 rs. 
Por dos libras y 20 onzas de esmalte a 10 rs. -21.6

Por una cuarta de cardenillo - 3.17 rs.

Por 4 barriles de humo de pez - 5 rs.

Por dos y media libras de aceite a $16-4.22$ rs.

Por 4 cuartiles de aceite de comer -2.28

Por 7 pinceles a 4 quartos -3.10 rs.

Todas las dichas pinturas se gastaron en la torre -63.23 rs.

Jornales para hacer los andamios de la torre

Primeramente para descubrir los mechinales de la torre $1 / 2$ jornal de un peón -2 rs.

Se comenzó a trabajar en los andamios el dia 22 del mes de mayo de 1756 años en este dicho dia se trabajó en los andamios el maestro 8 rs. y un peón a 4rs. -12 rs.

Desde el día 24 hasta el 29 de mayo los dichos - 12 rs.

En estos 7 días se hicieron los andamios de la dicha torre

Día 31 , día 1 de junio y 2, trabajó un peón en rascar la verdina de la torre y blanquearla -8 rs.

Jornales de albañilería

Día 14 de junio empezó el maestro con dos peones a trabajar en el remate de la dicha torre -16 rs.

Días 13, 16, 18, 19, 21 y 22 de junio los dichos - 16 rs. por día.

Jornales que se gastaron en cortar las cornisas, ladrillo y azulejos para el último cuerpo de la torre. Primeramente al que raspó los ladrillos alisares para las dichas cornisas se le pagó - 1 rs.

A un peón que asistió a el dicho raspador tres rs.

Mas a el maestro que trazó el dicho remate y cortó las 4 cornisas que dicho remate tiene por $8 \frac{1}{2}$ días de trabajo a $10 \mathrm{rs}$ - $85 \mathrm{rs}$.

Por el corte de azulejos y adeferas 5 días a 10 rs. -30 rs.

Jornales que se gastaron en reparar y rascar la dicha torre

Desde el día 23 hasta el 31 de julio el maestro y 2 peones - 16 rs. por día

Dicho día 29 trabajó un peón en apagar un poca de cal que se dio en la almona

En estos 7 días trabajó un hombre ganando 5 rs. En rascar la dicha torre, importa 35 rs.

Pintura de la torre hasta el tejado

Para pintar la dicha torre se gastaron 8 jornales a 7 rs. -56 rs.

Composición de la cruz, veleta y corona

Primeramente por aliñar la cruz y veleta costó - 12 rs.

Por el dorado de la cruz, veleta y corona al maestro Miguel de la Puerta se le dio - 105 rs.

Jornales que se gastaron en el alicatado de los azulejos 
Desde el día 29 de octubre se comenzó hasta el 3 de noviembre con el maestro y dos peones -16 rs. por día.

En estos 4 días se puso la cruz corona y se alicató el cuello último

Desde el día 4 al 8 de noviembre los dichos - 16 rs. por día.

En estos 4 días se alicató el segundo cuerpo del remate

Desde el día 9 hasta el 20 de noviembre los dichos - 16 rs. por día.

En estos 11 días se alicató la torre hasta la cornisa grande y se pusieron los remates

Desde el día 22 hasta el 25 de diciembre los dichos - 16 rs. por día.

En estos 4 días se alicató el cuerpo bajo de las campanas y se desbarataron los andamios

Días 26, 27, y 29 de noviembre, 1, 4, 16 y 17 de diciembre los dichos - 16 rs. por día.

Y en estos 7 días se renovó la torre desde el tejado hasta el suelo y se puso el lienzo de la Virgen y quedó concluida la obra de la dicha torre la víspera de Nuestra Señora de La O.

Pintura del bedriado

Por pintar los lienzos y remates de la torre por el maestro Joseph de Zúñiga paque al dicho $-60 \mathrm{rs}$.

Sumario general del gasto

En madera se gastó -- 82,26 rs.

En hierro - 55,11 rs.

En cal de Morón, yeso y arena - 25 rs.

En ladrillos varios - 190,17 rs.

En tralletas y espuertas $-10,3 \mathrm{rs}$.

En azulejos crudos y cocidos - 176,17 rs.

En pintura de la torre $-63,23$ rs.

Por la hechura de los andamios -86 rs.

Jornales de albañilería - 1071 rs.

1761,18 rs.

Yten. mas por la pintura de los lienzos - 60 rs.

1821,18 rs.

Montan las partidas de materiales y jornales gastados en la torre, un mil ochocientos veinte y un rrelaes y dieciocho maravedíes de vellón los que juntos con los dos mil trescientos trece reales y un maravedí de la obra de la iglesia montan quatro mil ciento treinta y cuatro reales y diez y nueve maravedís de las obras de la iglesia y torre $-4139,19$.

Gaspar Hermoso (rub.)

Gonzalo de Reyna (rub.) 


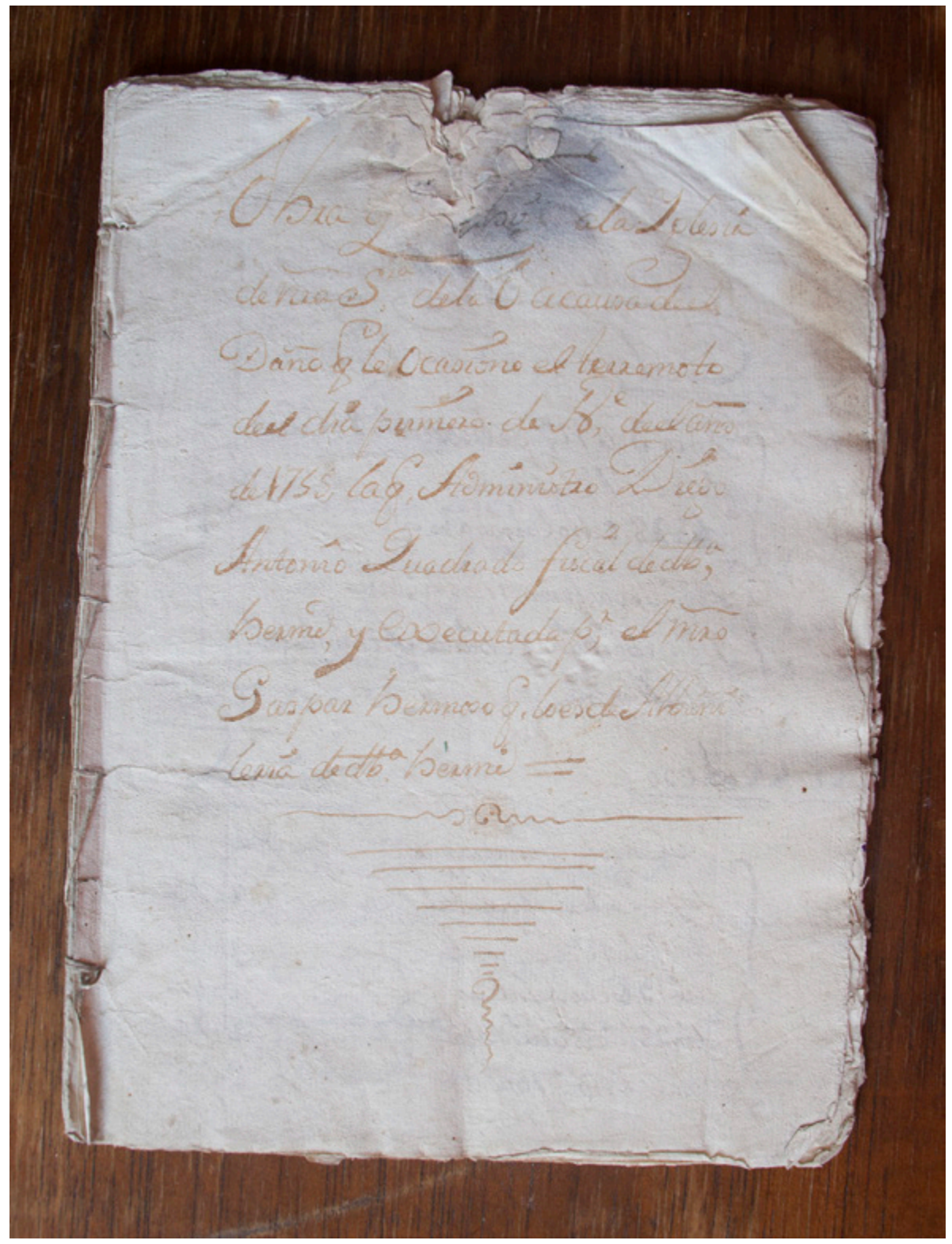

Figura 1. AHO, secc. VI-35, Obra que se hizo a la iglesia de Ntra. Sra. de la O a causa del daño que le ocasionó el terremoto del día primero de Noviembre del año 1755. 


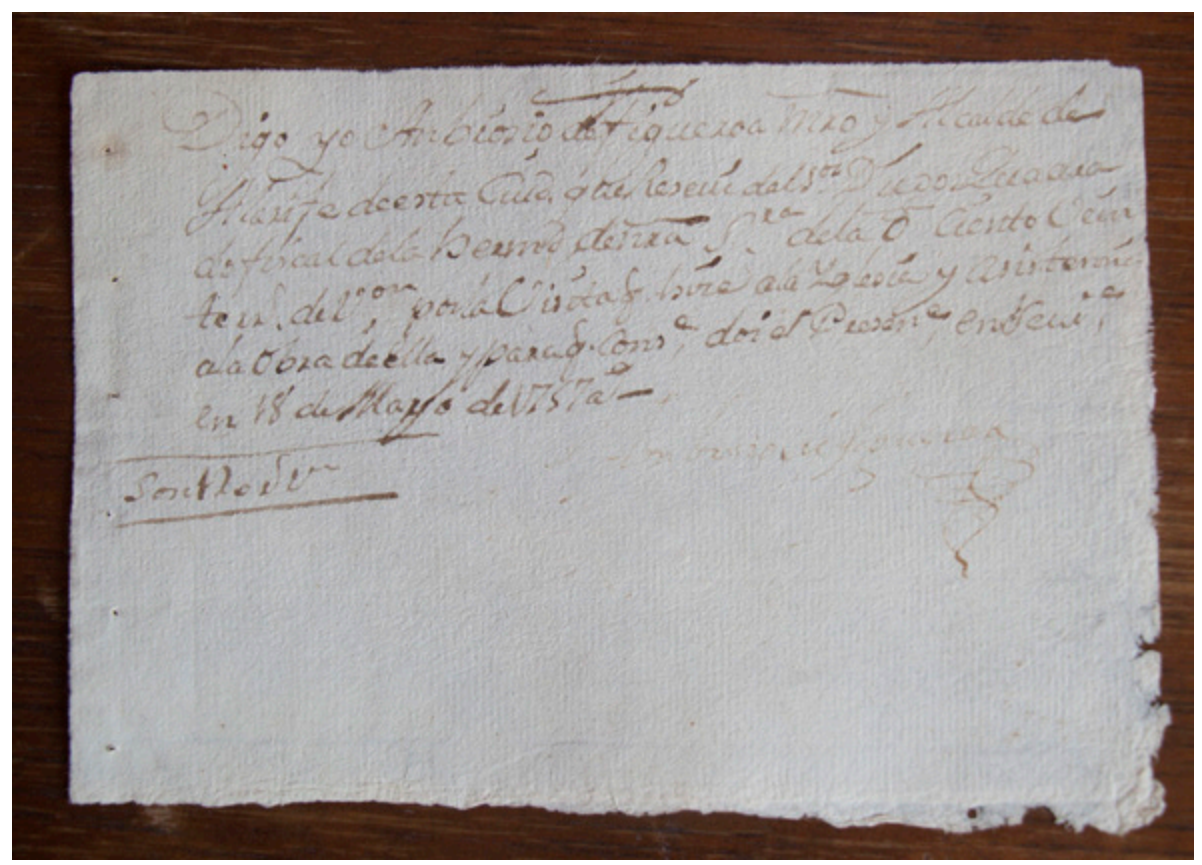

Figura 2. Recibo autógrafo de Ambrosio de Figueroa, 18-5-1757. 


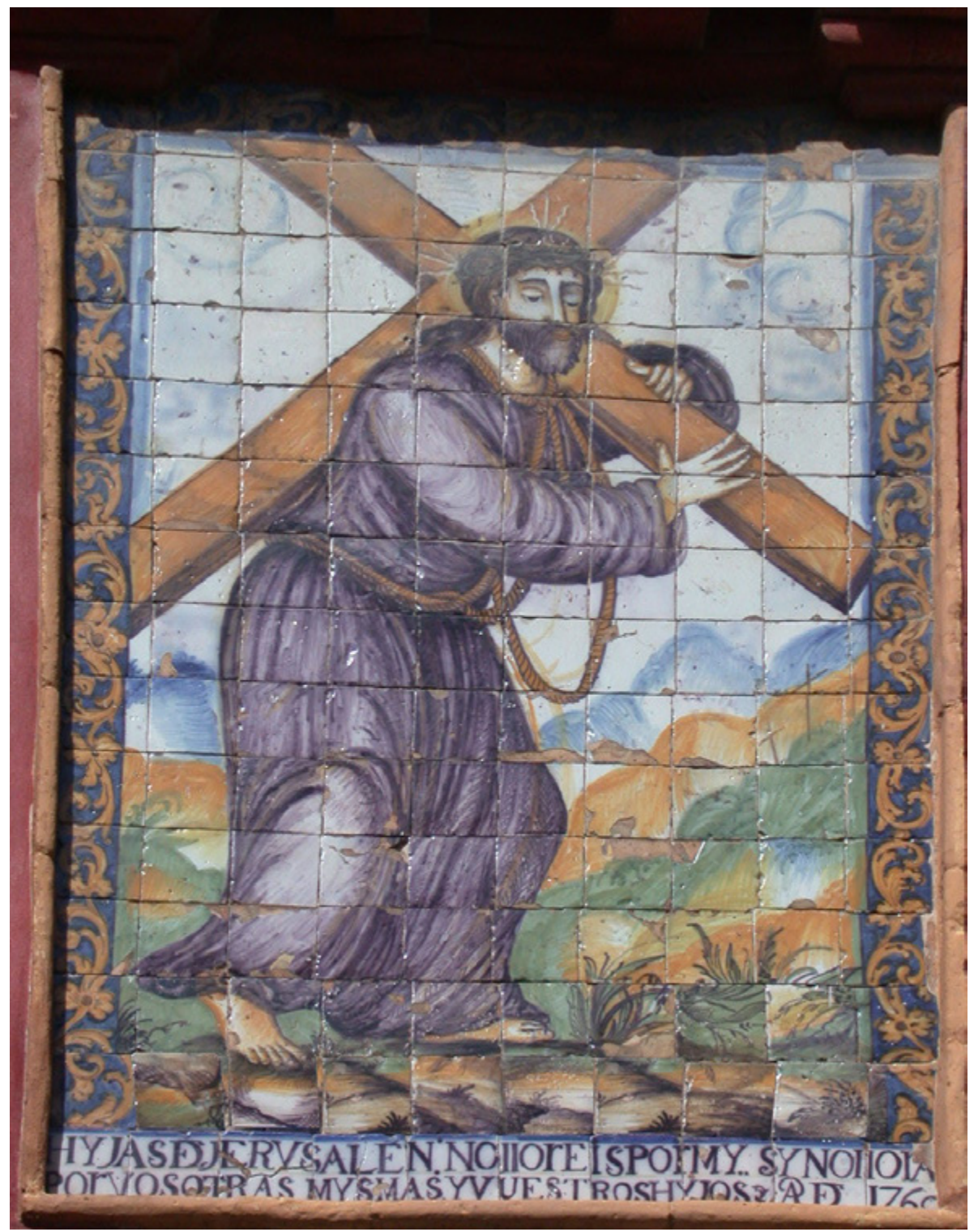

Figura 3. Juan Bernardo (vidriado) y José de Zúñiga (pintor ceramista), Retablo cerámico de Nuestro Padre Jesús Nazareno, 1756, iglesia de la O, Sevilla. 


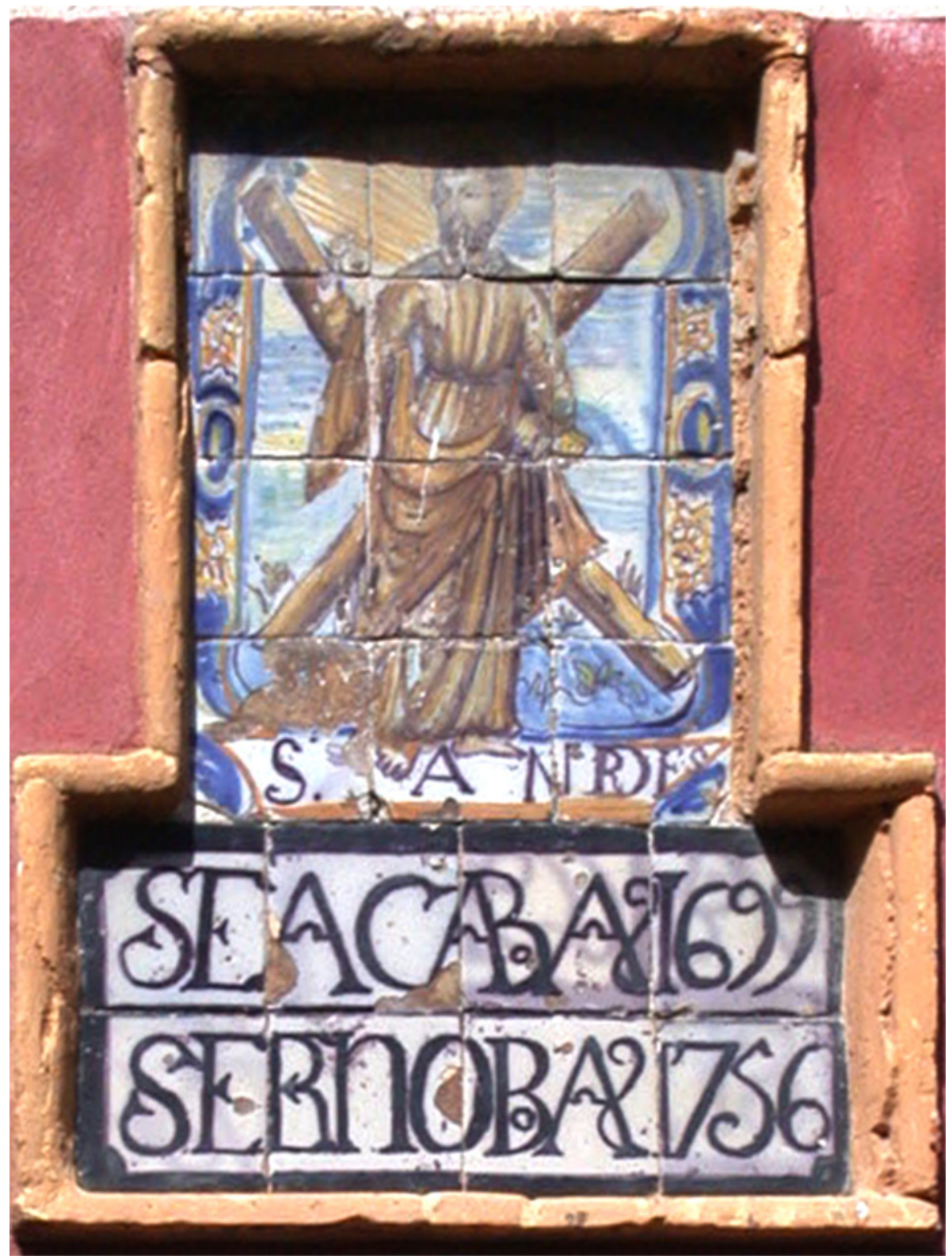

Figura 4. Juan Bernardo (vidriado) y José de Zúñiga (pintor ceramista), Retablo cerámico de San Andrés, 1756, iglesia de la O, Sevilla. 


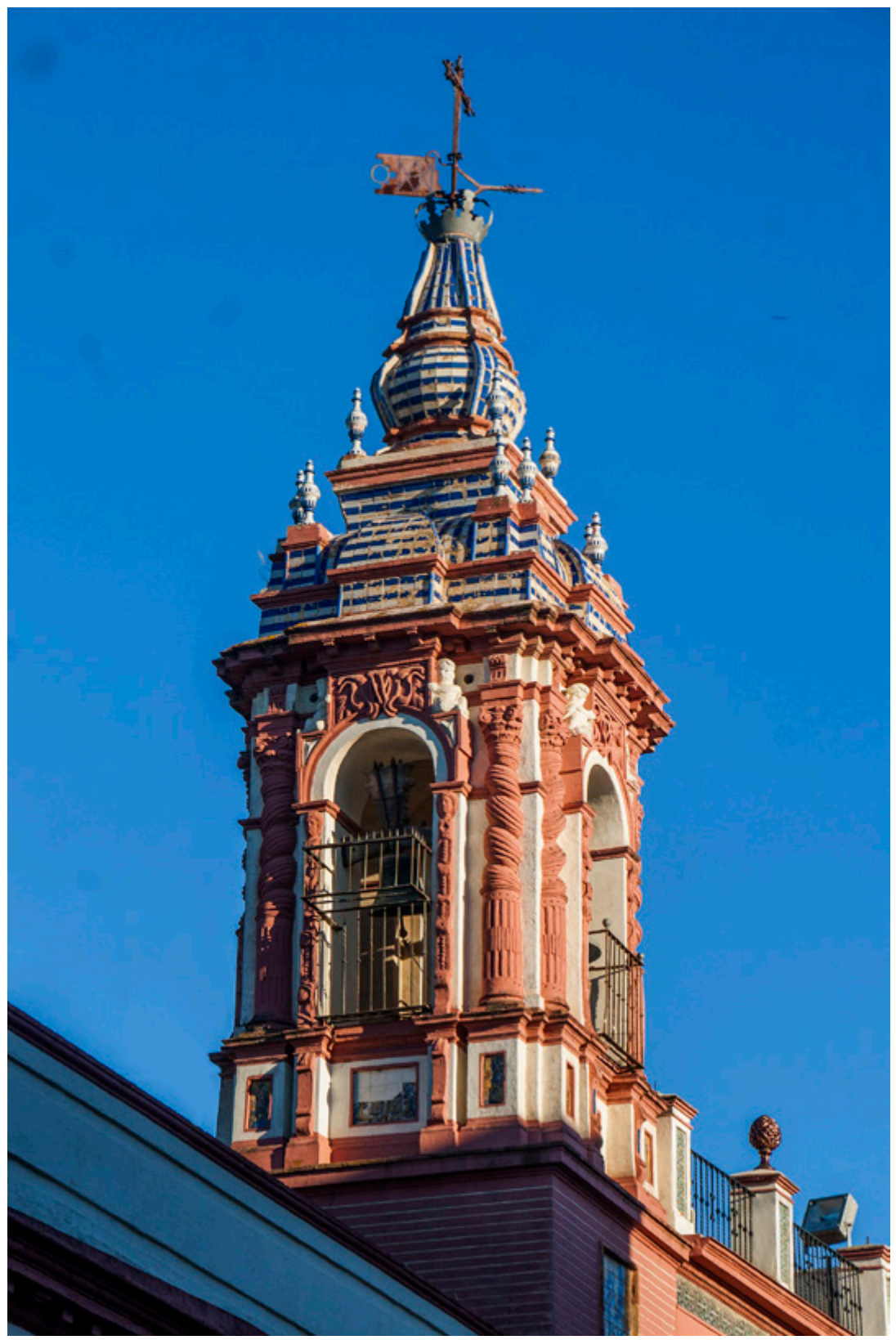

Figura 5. Pedro Romero, Ambrosio Figueroa y Gaspar Hermoso, Campanario y remate de la torre, 1699-1716, iglesia de la O, Sevilla. 